\title{
Epidemiologic Classification of Human Papillomavirus Types Associated with Cervical Cancer
}

\author{
Nubia Muñoz, M.D., F. Xavier Bosch, M.D., Silvia de Sanjosé, M.D., \\ Rolando Herrero, M.D., Xavier Castellsagué, M.D., Keerti V. Shah, Ph.D., \\ Peter J.F. Snijders, Ph.D., and Chris J.L.M. Meijer, M.D., for the International \\ Agency for Research on Cancer Multicenter Cervical Cancer Study Group*
}

ABSTRACT

From the International Agency for Research on Cancer, Lyons, France (N.M.); the Epidemiology and Cancer Registration Unit, Institut Català d'Oncologia, L'Hospitalet de Llobregat, Barcelona, Spain (F.X.B., S.S., X.C.); Costa Rican Foundation for Health Sciences, San José, Costa Rica (R.H.); the Department of Molecular Microbiology and Immunology, Johns Hopkins School of Public Health, Baltimore (K.V.S.); and the Department of Pathology, Vrije Universiteit Medical Center, Amsterdam (P.J.F.S. C.J.L.M.M.). Address reprint requests to Dr. Muñoz at the Servei d'Epidemiologia i Registre del Càncer, Institut Català d'Oncologia, Hospital Duran i Reynals, Av. Gran Via, s/n km. 2,7, 08907 L'Hospitalet de Llobregat, Barcelona, Spain, or at cris@ ico.scs.es.

*Members of the study group are listed in the Appendix.

N EnglJ Med 2003;348:518-27.

Copyright $(2003$ Massachusetts Medical Society.
BACKGROUN D

Infection with human papilloma virus (HPV) is the main cause of cervical cancer, but the risk associated with the various HPV types has not been adequately assessed.

\section{METHODS}

We pooled data from 11 case-control studies from nine countries involving 1918 women with histologically confirmed squamous-cell cervical cancer and 1928 control women. A common protocol and questionnaire were used. Information on risk factors was obtained by personal interviews, and cervical cells were collected for detection of HPV DNA and typing in a central laboratory by polymerase-chain-reaction-based assays (with MY09/MY11 and GP5+/6+ primers).

\section{RESULTS}

HPV DNA was detected in 1739 of the 1918 patients with cervical cancer (90.7 percent) and in 259 of the 1928 control women (13.4 percent). With the GP5+/6+ primer, HPV DNA was detected in 96.6 percent of the patients and 15.6 percent of the controls. The most common HPV types in patients, in descending order of frequency, were types 16, $18,45,31,33,52,58$, and 35 . Among control women, types 16, 18, 45, 31, 6, 58, 35, and 33 were the most common. For studies using the GP5+/6+ primer, the pooled odds ratio for cervical cancer associated with the presence of any HPV was 158.2 ( 95 percent confidence interval, 113.4 to 220.6). The odds ratios were over 45 for the most common and least common HPV types. Fifteen HPV types were classified as high-risk types $(16,18,31,33,35,39,45,51,52,56,58,59,68,73$, and 82$)$; 3 were classified as probable high-risk types (26, 53, and 66); and 12 were classified as low-risk types $(6,11,40$, $42,43,44,54,61,70,72,81$, and CP6108). There was good agreement between our epidemiologic classification and the classification based on phylogenetic grouping.

CONCLUSIONS

In addition to HPV types 16 and 18, types $31,33,35,39,45,51,52,56,58,59,68,73$, and 82 should be considered carcinogenic, or high-risk, types, and types 26, 53, and 66 should be considered probably carcinogenic. 
ERVICAL CANCER IS THE SECOND MOST common cancer in women worldwide, and it is the principal cancer of women in most developing countries, where 80 percent of cases occur. ${ }^{1}$ Molecular epidemiologic evidence clearly indicates that certain types of human papillomavirus (HPV) are the principal cause of invasive cervical cancer ${ }^{2-4}$ and cervical intraepithelial neoplasia. ${ }^{5,6}$ More than 80 HPV types have been identified, and about 40 can infect the genital tract. ${ }^{7}$

Genital HPV types have been subdivided into low-risk types, which are found mainly in genital warts, and high-risk types, which are frequently associated with invasive cervical cancer. There is, however, no consensus concerning the categorization of many HPV types with low prevalence according to risk. Moreover, the number of putative high-risk types varies from 13 to 19 , and only 11 HPV types $(16,18,31,33,35,39,45,51,52,56$, and 58) are consistently classified as entailing high risk. ${ }^{8-11}$ For these reasons, clear-cut criteria for classifying HPV types into low-risk and high-risk groups are needed. These criteria should be based on molecular epidemiologic studies that provide risk estimates and on functional evidence of the oncogenic potential of the various HPV types. A classification of HPV types based on their phylogenetic relationship has been proposed, 12 but it has not been tested epidemiologically.

In 1995, the International Agency for Research on Cancer (IARC) concluded that four case-control studies yielded sufficient evidence to classify HPV types 16 and 18 as human carcinogens, but the evidence was limited or inadequate for other types. ${ }^{13}$ Since then, we have completed seven additional case-control studies in other populations, using similar protocols and HPV DNA-detection assays. We report here the pooled data from the 11 studies. These results form the basis for an epidemiologic classification of HPV types associated with cervical cancer, which can be compared with the phylogenetic classification. This information is essential for planning prevention by HPV vaccines and for screening programs based on HPV testing.

\section{METHODS}

\section{STUDY DESIGN}

From 1985 to 1997, we conducted 11 studies in nine countries with a broad range of rates of incidence of cervical cancer. Nine studies dealt only with invasive cervical cancer, and two also dealt with in situ cervical cancer. The subjects were drawn from high-risk populations in Africa (Morocco ${ }^{14}$ and Mali ${ }^{15}$ ) and South America (Colombia, ${ }^{2,16}$ Brazil, ${ }^{17}$ Paraguay, ${ }^{18}$ and Peru ${ }^{19}$ ); intermediate-risk populations in Asia (Thailand ${ }^{20}$ and the Philippines ${ }^{21}$ ); and low-risk populations in Spain. ${ }^{2,16}$ The methods of selection of patients and controls are described in the original study reports. Briefly, the patients were women with newly diagnosed, histologically confirmed invasive or in situ squamouscell cervical cancer who had not received treatment. The control groups were population-based in the studies of invasive cervical cancer in Spain and Colombia and hospital-based or clinic-based in the other studies. They were frequency-matched to patients according to age (in five-year intervals) in all studies. The original histologic slides from which the diagnosis was made were reviewed by expert pathologists. All protocols were approved by the IARC and local ethics committees. Oral consent was obtained from the subjects in the Spanish and Colombian studies (which were initiated in 1985), consistent with the standard at the time. In the remaining studies, which were initiated later, written informed consent was obtained.

\section{COLLECTION OF DATA AND SPECIMENS}

The women were interviewed at the hospital by trained interviewers using a standardized questionnaire to elicit information on risk factors for cervical cancer. After the interview, all women underwent a pelvic examination performed by a gynecologist or nurse, and two cervical scrapings were collected for cytologic study and detection of HPV DNA. A tumor-biopsy specimen was taken from most patients and kept frozen.

\section{DETECTION, TYPING, AND PHYLOGENETIC GROUPING OF HPV DNA}

Detection of HPV DNA in cervical scrapings (exfoliated cells) and biopsy specimens was performed blindly in central laboratories with use of polymerase-chain-reaction (PCR)-based assays. Detailed protocols for these assays have been described. The relatively insensitive version of PCR primers for the L1 gene, MY09/MY11, was used in the Colombian and Spanish studies. ${ }^{22}$ The GP5+/6+ general primer system was used in the remaining studies. ${ }^{23}$ To detect the specific HPV types, oligohybridization methods were used for HPV types 16, 18, 31, $33,35,39,45,51,52,54$, and 56. A second round was performed for HPV types 6, 11, 26, 34, 40, 42, 


\begin{tabular}{|c|c|c|c|c|c|c|c|c|c|}
\hline \multirow{3}{*}{ HPV Type } & \multicolumn{4}{|c|}{ Infections with One HPV Type } & \multicolumn{5}{|c|}{ Infections with Multiple HPV Types } \\
\hline & \multicolumn{2}{|r|}{ Patients } & \multicolumn{2}{|r|}{ Controls } & \multirow[t]{2}{*}{ HPV Types } & \multicolumn{2}{|r|}{ Patients } & \multicolumn{2}{|r|}{ Controls } \\
\hline & no. & $\begin{array}{c}\% \text { of all } \\
\text { infected patients }\end{array}$ & no. & $\begin{array}{c}\% \text { of all } \\
\text { infected controls }\end{array}$ & & no. & $\begin{array}{c}\% \text { of all } \\
\text { infected patients }\end{array}$ & no. & $\begin{array}{c}\% \text { of all } \\
\text { infected controls }\end{array}$ \\
\hline 16 & 950 & 54.6 & 63 & 24.3 & 16 and 18 & 36 & 2.1 & 3 & 1.2 \\
\hline 18 & 192 & 11.0 & 19 & 7.3 & 16 and 33 & 9 & 0.5 & 0 & 0.0 \\
\hline 45 & 77 & 4.4 & 9 & 3.5 & 16 and 31 & 6 & 0.3 & 1 & 0.4 \\
\hline 31 & 59 & 3.4 & 11 & 4.2 & 16 and 45 & 3 & 0.2 & 0 & 0.0 \\
\hline 52 & 38 & 2.2 & 4 & 1.5 & 16 and 51 & 3 & 0.2 & 0 & 0.0 \\
\hline 33 & 35 & 2.0 & 4 & 1.5 & 16 and 56 & 2 & 0.1 & 0 & 0.0 \\
\hline 58 & 34 & 2.0 & 6 & 2.3 & 16 and 58 & 2 & 0.1 & 0 & 0.0 \\
\hline 35 & 24 & 1.4 & 7 & 2.7 & 16 and 66 & 2 & 0.1 & 0 & 0.0 \\
\hline 59 & 20 & 1.2 & 1 & 0.4 & 16 and 6 & 2 & 0.1 & 0 & 0.0 \\
\hline 51 & 13 & 0.7 & 4 & 1.5 & 16 and 73 & 2 & 0.1 & 0 & 0.0 \\
\hline 56 & 11 & 0.6 & 5 & 1.9 & 16 and other types & 5 & 0.3 & 2 & 0.8 \\
\hline 39 & 9 & 0.5 & 0 & 0.0 & & & & & \\
\hline 73 & 6 & 0.3 & 1 & 0.4 & 18 and 45 & 9 & 0.5 & 1 & 0.4 \\
\hline 82 & 5 & 0.3 & 0 & 0.0 & 18 and 33 & 4 & 0.2 & 0 & 0.0 \\
\hline 26 & 3 & 0.2 & 0 & 0.0 & 18 and 52 & 3 & 0.2 & 1 & 0.4 \\
\hline 66 & 3 & 0.2 & 0 & 0.0 & 18 and 26 & 2 & 0.1 & 0 & 0.0 \\
\hline 68 & 2 & 0.1 & 1 & 0.4 & 18 and 58 & 2 & 0.1 & 0 & 0.0 \\
\hline$H R^{*}$ & 2 & 0.1 & 0 & 0.0 & 18 and other types & 2 & 0.1 & 1 & 0.4 \\
\hline 53 & 1 & 0.1 & 0 & 0.0 & & & & & \\
\hline 6 & 1 & 0.1 & 6 & 2.3 & 31 and 33 & 3 & 0.2 & 0 & 0.0 \\
\hline 81 & 1 & 0.1 & 6 & 2.3 & 31 and 52 & 2 & 0.1 & 0 & 0.0 \\
\hline 11 & 1 & 0.1 & 2 & 0.8 & 31 and other types & 2 & 0.1 & 4 & 1.5 \\
\hline 43 & 0 & 0.0 & 3 & 1.2 & & & & & \\
\hline 40 & 0 & 0.0 & 2 & 0.8 & 33 and 35 & 3 & 0.2 & 1 & 0.4 \\
\hline 42 & 0 & 0.0 & 1 & 0.4 & 33 and 58 & 3 & 0.2 & 0 & 0.0 \\
\hline 44 & 0 & 0.0 & 1 & 0.4 & 33 and other types & 2 & 0.1 & 1 & 0.4 \\
\hline
\end{tabular}

$43,44,53,58,59$, and 68 . A third round was performed for HPV types 57, 61, 66, 70, 72, 73, 81 (CP8304), 82 (W13B/MM4 subtype and IS39 subtype), 83, and CP6108. Specimens that were positive on assays with the GP5+/6+ system but that did not hybridize with any of these 33 probes were coded as HPV type X. Amplification of a fragment of the $\beta$-globin gene was used to assess the quality of the target DNA.
For specimens from patients found to be negative for $\beta$-globin and HPV DNA or positive for HPV X, DNA was extracted from the cell pellets and retested as described above. For detection of HPV in biopsy specimens, the sandwich method was used to check the histologic evidence of cancer, and an additional HPV-type-specific PCR was performed, with use of an E7 primer, for $14 \mathrm{HPV}$ types $(16,18,31,33,35,39,45,51,52,56,58,59,66$, and 


\begin{tabular}{|c|c|c|c|c|c|c|c|c|c|}
\hline \multicolumn{10}{|l|}{ Table 1. (Continued.) } \\
\hline \multicolumn{5}{|c|}{ Infections with One HPV Type } & \multicolumn{5}{|c|}{ Infections with Multiple HPV Types } \\
\hline \multirow[t]{2}{*}{ HPV Type } & \multicolumn{2}{|r|}{ Patients } & \multicolumn{2}{|r|}{ Controls } & \multirow[t]{2}{*}{ HPV Types } & \multicolumn{2}{|r|}{ Patients } & \multicolumn{2}{|r|}{ Controls } \\
\hline & no. & $\begin{array}{c}\% \text { of all } \\
\text { infected patients }\end{array}$ & no. & $\begin{array}{c}\% \text { of all } \\
\text { infected controls }\end{array}$ & & no. & $\begin{array}{c}\% \text { of all } \\
\text { infected patients }\end{array}$ & no. & $\begin{array}{c}\% \text { of all } \\
\text { infected controls }\end{array}$ \\
\hline 54 & 0 & 0.0 & 3 & 1.2 & & & & & \\
\hline 61 & 0 & 0.0 & 1 & 0.4 & 45 and 43 & 2 & 0.1 & 1 & 0.4 \\
\hline 70 & 0 & 0.0 & 4 & 1.5 & 45 and other types & 5 & 0.3 & 5 & 1.9 \\
\hline 72 & 0 & 0.0 & 4 & 1.5 & & & & & \\
\hline CP6108 & 0 & 0.0 & 1 & 0.4 & 6 and 11 & 1 & 0.1 & 4 & 1.5 \\
\hline \multirow[t]{5}{*}{$x_{\dagger}^{\dagger}$} & 111 & 6.4 & 54 & 20.8 & & & & & \\
\hline & & & & & $\begin{array}{l}\text { Other double } \\
\text { infections }\end{array}$ & 10 & 0.6 & 4 & 1.5 \\
\hline & & & & & Triple infections & 11 & 0.6 & 5 & 1.9 \\
\hline & & & & & Quadruple infections & 3 & 0.2 & 1 & 0.4 \\
\hline & & & & & Quintuple infections & 0 & 0.0 & 1 & 0.4 \\
\hline $\begin{array}{l}\text { Total no. of women } \\
\text { with single } \\
\text { infections }\end{array}$ & 1598 & 91.9 & 223 & 86.1 & $\begin{array}{l}\text { Total no. of women } \\
\text { with multiple } \\
\text { infections }\end{array}$ & 141 & 8.1 & 36 & 13.9 \\
\hline
\end{tabular}

* HR denotes that testing was performed for high-risk types, but that there was not sufficient material for further typing. $\dagger \mathrm{HPV}$ type $\mathrm{X}$ denotes specimens that were positive with the GP5+/6+ system but that did not hybridize with any of the 33 probes.

68) that were formerly designated as oncogenic types. ${ }^{4}$ These procedures were also used for reamplification of all control specimens classified as HPV $\mathrm{X}$ and a randomly selected subgroup of 32 specimens found to be positive for $\beta$-globin and negative for HPV DNA. After reamplification, 32 specimens from patients that were originally negative for HPV DNA were reclassified as positive for HPV DNA, but none of the specimens from control women were found to be positive for HPV DNA.

For patients, the combined prevalence of HPV DNA in exfoliated cells and in biopsy specimens is reported, whereas for control subjects, the prevalence of HPV DNA was determined only in exfoliated cells. Comparisons between patients and controls in which only the results from exfoliated cells were used produced virtually identical results.

For phylogenetic grouping of HPV types into low-risk or high-risk groups, we used the phylogenetic tree of 106 papillomavirus types based on an informative region within the L1 gene. ${ }^{24}$ The 12 HPV types that had been classified phylogenetically as high risk on the basis of sequence alignment, ${ }^{12}$ together with the types that are related to those 12 types, were classified as phylogenetically high risk in this study. Accordingly, among the $33 \mathrm{HPV}$ types that were specifically tested, types $16,31,33,35,52$, and 58 (all belonging to group A9); 18, 39, 45, 59, 68 , and 70 (group A7); 26, 51, and 82 (group A5); and 53, 56, and 66 (group A6) were phylogenetically classified as high-risk HPV types. In contrast, types 6,11, and 44 (group A10); 34 and 73 (group A11); 40 and 43 (group A8); 42 (group A1); 61, 72, 81, 83, 84, and CP6108 (group A3); and 57 (group A4) were classified as low-risk HPV types.

\section{STATISTICAL ANALYSIS}

To assess the risk of cervical cancer associated with HPV types, odds ratios and 95 percent confidence intervals were estimated by unconditional logistic regression. ${ }^{25}$ Odds ratios were adjusted for age as a categorical covariate (under 40, 40 to 49,50 to 59, and over 59 years). Because of the small number of subjects from Mali, two categories were used $(\leq 45$ and $>45$ years). Odds ratios for individual HPV types were estimated by categorizing, as a single variable, each type or category of types. Subjects with HPV DNA-negative results were used as the reference category.

We defined as high-risk HPV types those associ- 
ated, as single infections, with an odds ratio for cervical cancer of at least 5.0 and a lower 95 percent confidence limit of at least 3.0, as well as those that were detected in some of the patients but in none of the controls. We defined as low-risk HPV types those with an odds ratio for cervical cancer of at least 1.0 and a lower 95 percent confidence limit of less than 3.0, as well as those that were detected in some of the controls but in none of the patients. To test for a trend according to age in the prevalence of a specific HPV type among patients, the Mantel-Haenszel linear trend test was used. The Mantel-Haenszel test was used to test for homogeneity. All P values are two-sided.

\section{RESULTS}

\section{STUDY SUBJECTS}

A total of 2506 women with cervical cancer and 2491 control women were interviewed. Of the patients, 2365 (94.4 percent) had squamous-cell carcinoma and 141 (5.6 percent) had adenocarcinoma or adenosquamous carcinoma. A total of 1990 of the 2365 women with squamous-cell carcinoma (84.1 percent) and 2126 of the 2491 control women (85.3 percent) provided cervical specimens for HPV DNA testing.

Seventy-two of the 1990 specimens from patients (3.6 percent) and 198 of the 2126 control specimens (9.3 percent) tested for HPV DNA were negative for both $\beta$-globin and HPV and were excluded from the analysis, leaving 1918 patients and 1928 controls with specimens adequately tested for HPV DNA.

\section{SPECIFIC PREVALENCE OF HPV TYPES}

A total of 1739 patients ( 90.7 percent) were positive for HPV DNA. Of these, 91.9 percent were infected with a single HPV type, and 8.1 percent were infected with multiple types. Among control women, 259 (13.4 percent) were positive for HPV DNA; of these, 86.1 percent were infected by a single HPV type, and 13.9 percent were infected by multiple types (Table 1). In the studies in which the GP5+/6+ primers were used, the prevalence of HPV DNA was 96.6 percent in patients and 15.6 percent in controls. HPV types 16, 18, 45, 31, 33, 52, 58, and 35 (in descending order of frequency) were the eight most common types in patients, including infections with both single and multiple HPV types. HPV types 16, $18,45,31,6,58,35$, and 33 were the eight most common types in controls. The proportion of uncharacterized HPV types (HPV type $\mathrm{X}$ ) was higher in con- trols (20.8 percent) than in patients (6.4 percent) (Table 1). HPV types 34, 57, and 83 were not found in any specimens from patients or controls.

HPV type 16 was the most common type in all countries, with an overall prevalence of 58.9 percent, ranging from 43.9 percent in the Philippines to 72.4 percent in Morocco. HPV type 18 was the second most common type, with an overall prevalence of 15.0 percent (lowest in Spain [3.7 percent] and Colombia [4.4 percent] and highest in the Philippines [27.9 percent]). The third most common type, HPV type 45 (5.9 percent), had a very low prevalence in Spain and Colombia ( 0.8 percent and 0.6 percent, respectively), and its highest prevalence was in the Philippines (15.7 percent). HPV types 31 and 35 were more common in Latin America than in the other study areas. The prevalence of HPV type 52 was highest in Peru (8.6 percent). Some of the differences in type-specific prevalence observed between Spain and Colombia and the other countries could be related, at least in part, to differences in the sensitivities of the PCR assays used.

To explore the possibility of trends in the prevalence of HPV over time, the patients and controls were stratified into three groups according to age (Table 2). No statistically significant differences according to age in the distribution of HPV types (as single or multiple infections) were observed among the control women. Among the patients, the prevalence of HPV type 16 decreased significantly with age. Increases in prevalence with age were observed for types 39, 52, and 58 .

\section{RISK ASSOCIATED WITH HPV}

The prevalence of HPV DNA among patients and controls and the corresponding odds ratios, adjusted for age, are presented in Table 3 according to country. In the studies in which the GP5+/6+ system was used, the pooled odds ratio for cervical cancer associated with the presence of any HPV type was 158.2. When the MY09/MY11 primers were used, the pooled odds ratios were 63.4 and 19.1 in Spain and Colombia, respectively. The overall estimates of the odds ratio did not vary significantly according to age group. Adjustment for age slightly increased the odds ratios.

The adjusted odds ratios for the various HPV types are shown in Table 4. Data on patients and controls in Spain and Colombia have been excluded, because they were tested with a less sensitive PCR assay. For HPV types 16, 18, 31, 33, 35, 45, $51,52,56,58,59,68$, and 73 , the odds ratios were 


\begin{tabular}{|c|c|c|c|c|c|c|c|c|c|c|c|c|}
\hline \multirow[t]{3}{*}{ HPV Type } & \multicolumn{6}{|c|}{ Patients } & \multicolumn{6}{|c|}{ Controls } \\
\hline & & $\leq 34 \mathrm{yr}$ & & $35-49 \mathrm{yr}$ & & $\geq 50 \mathrm{yr}$ & & $\leq 34 \mathrm{yr}$ & & $35-49 \mathrm{yr}$ & & $\geq 50 \mathrm{yr}$ \\
\hline & no. & $\begin{array}{c}\% \text { of infected } \\
\text { patients }\end{array}$ & no. & $\begin{array}{l}\% \text { of infected } \\
\text { patients }\end{array}$ & no. & $\begin{array}{l}\% \text { of infected } \\
\text { patients }\end{array}$ & no. & $\begin{array}{l}\text { \% of infected } \\
\text { controls }\end{array}$ & no. & $\begin{array}{l}\% \text { of infected } \\
\text { controls }\end{array}$ & no. & $\begin{array}{l}\text { \% of infected } \\
\text { controls }\end{array}$ \\
\hline $16 *$ & 175 & 64.1 & 417 & 60.0 & 433 & 56.2 & 12 & 28.6 & 29 & 24.8 & 29 & 29.0 \\
\hline 18 & 33 & 12.1 & 113 & 16.3 & 114 & 14.8 & 0 & 0.0 & 14 & 12.0 & 12 & 12.0 \\
\hline 45 & 14 & 5.1 & 54 & 7.8 & 34 & 4.4 & 4 & 9.5 & 6 & 5.1 & 8 & 8.0 \\
\hline 31 & 11 & 4.0 & 33 & 4.7 & 29 & 3.8 & 5 & 11.9 & 5 & 4.3 & 7 & 7.0 \\
\hline $52 \dagger$ & 1 & 0.4 & 11 & 1.6 & 34 & 4.4 & 0 & 0.0 & 3 & 2.6 & 3 & 3.0 \\
\hline 33 & 8 & 2.9 & 27 & 3.9 & 29 & 3.8 & 3 & 7.1 & 2 & 1.7 & 4 & 4.0 \\
\hline $58 *$ & 3 & 1.1 & 15 & 2.2 & 26 & 3.4 & 2 & 4.8 & 3 & 2.6 & 6 & 6.0 \\
\hline 35 & 6 & 2.2 & 7 & 1.0 & 21 & 2.7 & 2 & 4.8 & 4 & 3.4 & 4 & 4.0 \\
\hline 59 & 1 & 0.4 & 10 & 1.4 & 12 & 1.6 & 0 & 0.0 & 0 & 0.0 & 2 & 2.0 \\
\hline 51 & 1 & 0.4 & 10 & 1.4 & 9 & 1.2 & 1 & 2.4 & 4 & 3.4 & 1 & 1.0 \\
\hline 56 & 0 & 0.0 & 6 & 0.9 & 10 & 1.3 & 2 & 4.8 & 2 & 1.7 & 3 & 3.0 \\
\hline $39 *$ & 0 & 0.0 & 5 & 0.7 & 11 & 1.4 & 0 & 0.0 & 0 & 0.0 & 1 & 1.0 \\
\hline 73 & 0 & 0.0 & 4 & 0.6 & 6 & 0.8 & 1 & 2.4 & 1 & 0.9 & 0 & 0.0 \\
\hline 82 & 1 & 0.4 & 0 & 0.0 & 5 & 0.6 & 1 & 2.4 & 1 & 0.9 & 0 & 0.0 \\
\hline 26 & 1 & 0.4 & 0 & 0.0 & 4 & 0.5 & 0 & 0.0 & 0 & 0.0 & 0 & 0.0 \\
\hline 66 & 1 & 0.4 & 3 & 0.4 & 5 & 0.6 & 0 & 0.0 & 0 & 0.0 & 0 & 0.0 \\
\hline 68 & 0 & 0.0 & 2 & 0.3 & 1 & 0.1 & 1 & 2.4 & 0 & 0.0 & 2 & 2.0 \\
\hline 53 & 1 & 0.4 & 1 & 0.1 & 1 & 0.1 & 0 & 0.0 & 0 & 0.0 & 0 & 0.0 \\
\hline 6 & 2 & 0.7 & 4 & 0.6 & 3 & 0.4 & 4 & 9.5 & 4 & 3.4 & 5 & 5.0 \\
\hline 81 & 0 & 0.0 & 0 & 0.0 & 2 & 0.3 & 1 & 2.4 & 2 & 1.7 & 5 & 5.0 \\
\hline 70 & 0 & 0.0 & 0 & 0.0 & 2 & 0.3 & 0 & 0.0 & 5 & 4.3 & 2 & 2.0 \\
\hline Others & 2 & 0.7 & 7 & 1.0 & 5 & 0.6 & 7 & 16.7 & 13 & 11.1 & 13 & 13.0 \\
\hline$x+$ & 30 & 11.0 & 35 & 5.0 & 46 & 6.0 & 7 & 16.7 & 32 & 27.4 & 15 & 15.0 \\
\hline $\begin{array}{l}\text { Total no. of infected } \\
\text { women }\end{array}$ & 273 & 100.0 & 695 & 100.0 & 771 & 100.0 & 42 & 100.0 & 117 & 100.0 & 100 & 100.0 \\
\hline Total no. of infections & 291 & - & 764 & - & 842 & - & 53 & - & 130 & - & 122 & - \\
\hline
\end{tabular}

over 45 and the lower confidence limits were all higher than 4.0. They were therefore classified as high-risk types.

HPV types 39 and 82 were also classified as highrisk types, because they were detected in some patients but in none of the 1928 controls. Because types 26, 53, and 66 were detected in only one to three patients, these types were classified as probable high-risk types (Table 1 ).

HPV types 40, 42, 43, 44, 54, 61, 70, 72, and CP6108 were not detected in patients and were considered low-risk types. Types 6, 11, and 81 were 


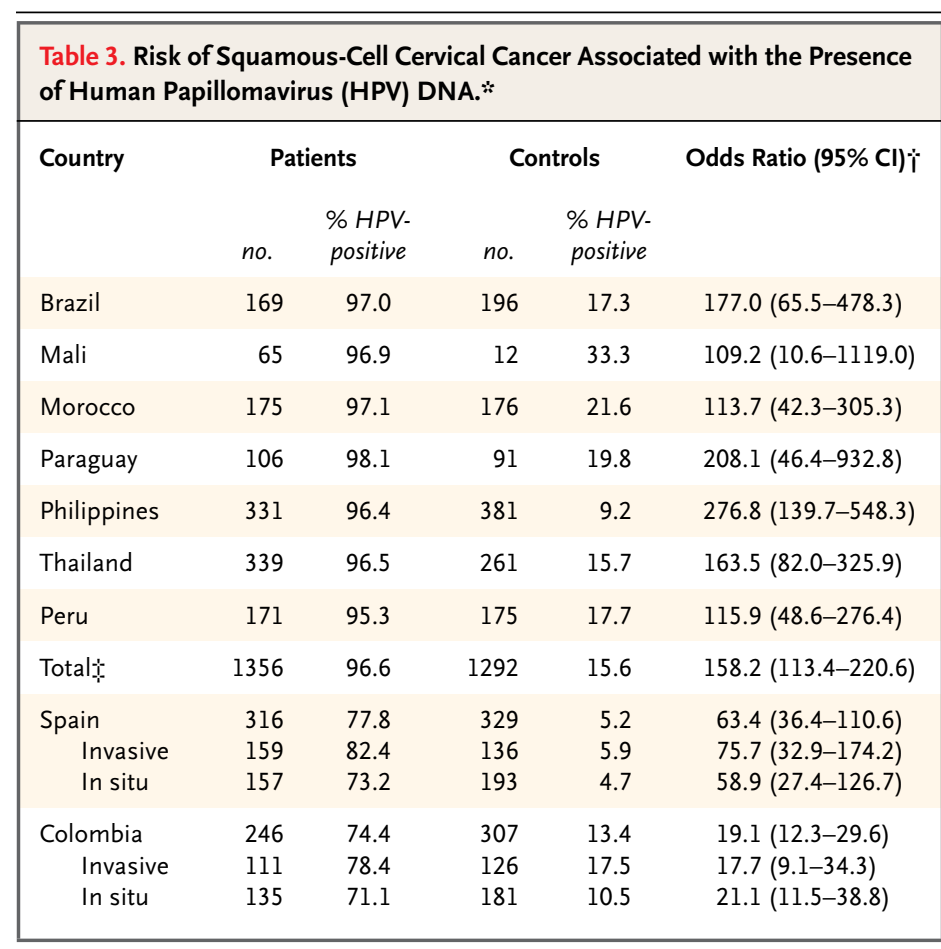

* Testing was performed with the GP5+/6+ primers, except in Spain and Colombia, where the MY09/MYll primers were used. For all countries except Spain and Colombia, only invasive cancer was studied.

$\dagger$ The odds ratios have been adjusted for age. $\mathrm{Cl}$ denotes confidence interval. $\uparrow$ The odds ratio has been adjusted for age and center.

each detected in only 1 of the 1598 patients positive for single HPV types, and were therefore also classified as low-risk types (Table 1). Although the odds ratios for types 6 and 11 were 4.3 and 11.2, respectively, the lower limits of their confidence intervals were 0.5 and 1.0, respectively, further supporting their classification in the low-risk group.

The odds ratio for infection with multiple HPV types was not significantly different from that for infection with a single type (odds ratio for cervical cancer associated with multiple as compared with single infection, 0.7 ; 95 percent confidence interval, 0.4 to 1.0 ).

When our epidemiologic classification was compared with the phylogenetic grouping (Table 5), a discrepancy was observed only for two types: HPV type 70, which was classified as a high-risk type phylogenetically but as a low-risk type by our epidemiologic study; and HPV type 73, which was classified as a low-risk type phylogenetically but a high-risk type epidemiologically.

No significant interactions were detected between HPV type and other known risk factors, such as high parity, long-term use of oral contraceptives, smoking, and age at first sexual intercourse (data not shown).

\section{I SCUSS I O N}

Our pooled analysis of 11 case-control studies provides robust estimates of the risk of squamous-cell carcinoma of the cervix linked to $30 \mathrm{HPV}$ types. Our best estimate of the pooled odds ratio for squamous-cell cervical carcinoma associated with HPV DNA positivity is 158.2 (Table 3). The association with the less common types is of a strength similar to the association found with HPV types 16 and 18.

Retesting of all patients who were negative for HPV DNA, but of only a small proportion of controls who were negative for HPV DNA, as well as the use of biopsy specimens from some of the patients, could have led to overestimation of the true odds ratios associated with HPV infection. However, we believe that any potential bias is likely to be small and would not substantially modify our results. In our validation studies in Peru, 19 of the 29 patients originally classified as negative for HPV DNA were reclassified as positive after retesting with $\mathrm{E} 7$ primers, whereas none of the controls were reclassified as positive. ${ }^{19}$ Similarly, in another study carried out in Thailand, the Philippines, and Spain, the prevalence of HPV DNA in exfoliated cells was very close to that in cervical-biopsy specimens from women without cervical cancer who were undergoing hysterectomy. ${ }^{26}$

Our epidemiologic classification, based on HPV-type-specific odds ratios and HPV prevalence among patients and controls, identified $15 \mathrm{HPV}$ types as high-risk types $(16,18,31,33,35,39,45$, $51,52,56,58,59,68,73$, and 82). Three types ( 26 , 53 , and 66) should be considered probable highrisk types, since they were detected in only one to three patients and in none of the controls. Twelve types $(6,11,40,42,43,44,54,61,70,72,81$, and CP6108) were categorized as low-risk types, and three types $(34,57$, and 83 ) were detected in none of the samples and were therefore considered to be associated with undetermined risk. According to the results of our study, five types that others have classified as low-risk types ${ }^{10,27}$ or as types associated with undetermined risk ( $26,53,66,73$, and 82$)$ should now be added to the list of high-risk or probable high-risk types. The commercially available Hybrid Capture II (Digene) high-risk HPV test includes all of the types we have classified as high-risk types 
EPIDEMIOLOGIC CLASSIFICATION OF HPV TYPES ASSOCIATED WITH CERVICAL CANCER

\begin{tabular}{|c|c|c|c|c|c|}
\hline \multirow[t]{2}{*}{ HPV Type } & \multicolumn{2}{|c|}{ Patients } & \multicolumn{2}{|c|}{ Controls } & \multirow[t]{2}{*}{ Odds Ratio $(95 \% \mathrm{Cl}) \hat{\mathrm{i}}$} \\
\hline & no. & $\%$ & no. & $\%$ & \\
\hline Negative for HPV & 46 & 3.4 & 1091 & 84.4 & 1.0 \\
\hline 16 & 685 & 50.5 & 42 & 3.3 & $434.5(278.2-678.7)$ \\
\hline 18 & 177 & 13.1 & 17 & 1.3 & $248.1(138.1-445.8)$ \\
\hline 45 & 74 & 5.5 & 9 & 0.7 & $197.6(91.7-425.7)$ \\
\hline 31 & 36 & 2.7 & 8 & 0.6 & $123.6(53.5-286.0)$ \\
\hline 52 & 37 & 2.7 & 4 & 0.3 & $200.0(67.8-590.1)$ \\
\hline 33 & 14 & 1.0 & 1 & 0.1 & $373.5(46.7-2985.8)$ \\
\hline 58 & 31 & 2.3 & 6 & 0.5 & $114.8(45.1-292.6)$ \\
\hline 35 & 15 & 1.1 & 6 & 0.5 & $73.8(26.4-206.5)$ \\
\hline 59 & 17 & 1.3 & 1 & 0.1 & $419.2(54.2-3242.4)$ \\
\hline 51 & 13 & 1.0 & 4 & 0.3 & $66.5(20.0-221.0)$ \\
\hline 56 & 9 & 0.7 & 5 & 0.4 & $45.1(14.0-145.3)$ \\
\hline 39 & 8 & 0.6 & 0 & 0.0 & - \\
\hline 73 & 5 & 0.4 & 1 & 0.1 & $106.4(11.4-991.8)$ \\
\hline 68 & 2 & 0.2 & 1 & 0.1 & $53.7(4.4-650.1)$ \\
\hline 6 & 1 & 0.1 & 6 & 0.5 & $4.3(0.5-38.4)$ \\
\hline 11 & 1 & 0.1 & 2 & 0.2 & $11.2(1.0-128.0)$ \\
\hline 81 & 0 & 0.0 & 6 & 0.5 & - \\
\hline$x+$ & 47 & 3.5 & 34 & 2.6 & $32.9(19.1-56.6)$ \\
\hline Other single HRJ & 10 & 0.7 & 0 & 0.0 & - \\
\hline Other single LR & 0 & 0.1 & 19 & 1.5 & - \\
\hline 16 and other LR & 5 & 0.4 & 1 & 0.1 & $130.8(14.7-1161.7)$ \\
\hline 16 and other HR & 23 & 1.7 & 1 & 0.1 & $617.4(80.8-4716.4)$ \\
\hline 16 and 18 & 36 & 2.7 & 3 & 0.2 & $327.2(95.7-1119.1)$ \\
\hline 18 and other $H R$ & 21 & 1.5 & 3 & 0.2 & $187.0(52.8-662.3)$ \\
\hline Other double infections & 29 & 2.1 & 15 & 1.2 & $52.3(25.6-106.7)$ \\
\hline Triple infections & 10 & 0.7 & 4 & 0.3 & $65.4(19.3-221.7)$ \\
\hline Quadruple or quintuple infections & 3 & 0.2 & 2 & 0.2 & $32.5(5.1-206.8)$ \\
\hline Total women & 1356 & 100.0 & 1292 & 100.0 & \\
\hline Multiple infections & 127 & 9.4 & 29 & 2.2 & $114.9(68.8-191.7)$ \\
\hline Single infections & 1183 & 87.2 & 172 & 13.3 & $172.6(122.2-243.7)$ \\
\hline \multicolumn{6}{|c|}{$\begin{array}{l}\text { * } \mathrm{Cl} \text { denotes confidence interval, HR high-risk types, and LR low-risk types. Women from Spain and Colombia have been excluded } \\
\text { from this analysis. } \\
\text { The odds ratios were adjusted for age and center. } \\
\text { THPV type X denotes specimens that were positive with the GP5+/6+ system but that did not hybridize with any of the } 33 \text { probes } \\
\text { This category includes HPV types } 26,66,82 \text {, and HR. } \\
\text { 9 This category includes HPV types } 54,43,40,42,44,61,70,72 \text {, and CP6108. }\end{array}$} \\
\hline
\end{tabular}




\begin{tabular}{|c|c|c|}
\hline \multicolumn{3}{|c|}{$\begin{array}{l}\text { Table 5. Phylogenetic and Epidemiologic Classification } \\
\text { of HPV Types. }\end{array}$} \\
\hline \multirow[t]{2}{*}{$\begin{array}{l}\text { Phylogenetic } \\
\text { Classification }\end{array}$} & Epidemiologic & Classification \\
\hline & High risk & Low risk \\
\hline High risk & $\begin{array}{l}16,18,31,33,35,39 \\
45,51,52,56,58,59 \\
68,82,26, * 53, * 66 *\end{array}$ & 70 \\
\hline Low risk & 73 & $\begin{array}{c}6,11,40,42,43,44 \\
54,61,72,81 \\
\text { CP } 6108\end{array}$ \\
\hline
\end{tabular}

* The epidemiologic classification of these types as probable high-risk types is based on zero controls and one to three positive cases.

except types $26,53,66,73$, and $82 .{ }^{10}$ Our results indicate that this assay would have missed 18 of 1598 infections in patients (1.1 percent) and 1 of 223 in controls ( 0.4 percent).

We confirmed the low-risk status of six types widely regarded as such (types 6, 11, 40, 42, 43, and 44) and added to this list types 54, 61, 70, 72, 81, and CP6108, which have been considered as types associated with undetermined risk by others. Further studies will be required to determine the epidemiologic classification of HPV types not assessed in our study, such as types 62 and 67, which are classified phylogenetically as low-risk and high-risk types, respectively.

This pooled analysis provided us with the opportunity to compare epidemiologic and phylogenetic classifications of HPV types. The concordance of these two classifications is remarkable (Table 5); discrepancies were found only for types 70 and 73 .

Little is known about the transforming or oncogenic properties of the E6 and E7 genes of HPV types other than those of the prototype high-risk types (16 and 18) and low-risk types ( 6 and 11). Types 16 and 18 , as well as types 31 and 33, but not types 6 and 11, can induce immortalization of primary human keratinocytes and rat kidney cells. ${ }^{28-30}$

The prevalence of multiple HPV infections varies in relation to the method used to detect HPV
DNA. ${ }^{10}$ In our study, the use of the PCR assay with the GP5+16+ primer system may have led to an underestimation of the prevalence of multiple infections. As in previous studies, infection by multiple HPV types in our study was not associated with a greater risk of cervical cancer than infection by a single HPV type. ${ }^{27,31}$

HPV type 16 was the only type whose incidence decreased significantly with age. Assessment of the distribution of HPV types in cervical cancer over the past four to five decades is needed to determine whether these age-related differences are due to a cohort effect that could predict changes in the distribution of HPV types in the years to come, with implications for HPV-vaccination efforts.

Types $16,18,45,31,33,52,58$, and 35 accounted for 95 percent of the squamous-cell carcinomas positive for HPV DNA. These findings have important implications for the prevention of cervical cancer. They imply that an effective vaccine against the five most common HPV types could prevent about 90 percent of the cases of cervical cancer worldwide. However, regional variation in the distribution of certain HPV types should be taken into account in the creation of vaccines tailored to different geographic regions.

Our results also have important implications for patient care and screening strategies. The similarity of the odds ratios for individual high-risk HPV types and their combinations clearly indicates that testing for groups of high-risk HPV types is sufficient and that the composition of screening "cocktails" for high-risk HPV types could be revised in view of our results and those from other populations.

Supported in part by grants from the Spanish Ministerio de Educación, Cultura y Deporte for short-term visiting scientists (SAB20000261, to Dr. Muñoz), the Fondo de Investigaciones Sanitarias, Spain (FIS 01/1236, FIS 01/1237, and BAE 01/5013), the Programa Interministerial de Investigación y Desarrollo, Spain (SAF 96/0323), and the Preventiefonds, the Netherlands (28-1502.1).

We are indebted to Mireia Díaz and Annie Arslan for statistical analysis and data management; to Cristina Rajo for her secretarial assistance; to René Pol, Jolein Pleijster, and Nathalie FransenDaalmeijer for their expert technical assistance; to Victor Moreno at the Institut Català d'Oncologia for useful comments on the manuscript; and to the gynecologists, pathologists, and supervisors of the fieldwork in the studies and to the many persons who volunteered to participate in them.

\section{APPENDIX}

The International Agency for Research on Cancer Multicenter Cervical Cancer Study Group is composed of the following researchers: N. Muñoz, S. Franceschi, M. Plummer, and J. Smith (International Agency for Research on Cancer, Lyons, France); F.X. Bosch, V. Moreno, S. de Sanjosé, and X. Castellsagué (Institut Català d'Oncologia, Barcelona, Spain); R. Herrero (Foundation for Health Sciences, San José, Costa Rica); C.J.L.M. Meijer, J.M.M. Walboomers (deceased), A.J.C. van den Brule, and P.J.F. Snijders (Vrije Universiteit Medical Center, Amsterdam); K.V. Shah (Johns Hopkins University, Baltimore); S. Chichareon (Prince of Songkla University, Hat-Yai, Thailand); C. Ngelangel (University of the Philippines, Manila); N. Chaouki and B. El Gueddari (Institut National d'Oncologie, Rabat, Morocco); J. Eluf Neto (São Paulo 
University, São Paulo, Brazil); P.A. Rolón (Laboratorio de Anatomía Patológica y Citología, Asunción, Paraguay); C. Santos and E. Caceres (Maes Heller Cancer Research Institute, Lima, Peru); S. Bayo (Institut National de Recherche en Santé Publique, Bamako, Mali); I. Izarzugaza (Euskadi Cancer Registry, Vitoria Gasteiz, Spain); M. Gili (Cátedra de Medicina Preventiva y Social, Seville, Spain); P. Viladiu (Cancer Registry of Catalunya, Barcelona, Spain); L.A. Tafur (University of Valle, Cali, Colombia); C. Navarro (Health Council, Murcia, Spain); N. Ascunce (Breast Cancer Prevention Center, Pamplona, Spain); L.C. González (Delegation of Social Welfare, Salamanca, Spain); M. Santamaria (Navarra Hospital, Pamplona, Spain); P. Alonso de Ruiz (General Hospital of Mexico, Mexico City); N. Aristizabal (Cali, Colombia); and J. Deacon (Institute of Cancer Research, Belmont, United Kingdom).

REFERENCES

1. Ferlay J, Bray F, Pisani P, Parkin DM. Globocan 2000: cancer incidence, mortality and prevalence worldwide, version 1.0. IARC CancerBase no. 5. Lyons, France: IARC Press 2001.

2. Muñoz N, Bosch FX, de Sanjosé S, et al. The causal link between human papillomavirus and invasive cervical cancer: a population-based case-control study in Colombia and Spain. Int J Cancer 1992;52:743-9.

3. Bosch FX, Lorincz A, Munoz N, Meije CJ, Shah KV. The causal relation between human papillomavirus and cervical cancer. J Clin Pathol 2002;55:244-65.

4. Walboomers JMM, Jacobs MV, Mano $\mathrm{MM}$, et al. Human papillomavirus is a neces sary cause of invasive cervical cancer world wide. J Pathol 1999;189:12-9.

5. Schiffman MH, Bauer HM, Hoover RN et al. Epidemiologic evidence showing that human papillomavirus infection causes most cervical intraepithelial neoplasia. J Natl Cancer Inst 1993;85:958-64.

6. Kjaer SK, van den Brule AJC, BockJE, e al. Human papillomavirus - the most sig nificant risk determinant of cervical intraepithelial neoplasia. Int J Cancer 1996;65: 601-6.

7. de Villiers E-M. Taxonomic classification of papillomaviruses. Papillomavirus Rep 2001;12:57-63.

8. Jacobs MV, de Roda Husman AM, van den Brule AJC, Snijders PJF, Meijer CJLM Walboomers JMM. Group-specific differentiation between high- and low-risk human papillomavirus genotypes by general primer mediated PCR and two cocktails of oligonucleotide probes. J Clin Microbiol 1995;33. 901-5.

9. van den Brule AJ, Pol R, FransenDaalmeijer N, Schouls LM, Meijer CJLM, Snijders PJ. GP5+/6+ PCR followed by reverse line blot analysis enables rapid and high-throughput identification of human papillomavirus genotypes. J Clin Microbio 2002;40:779-87.

10. Davies P, Kornegay J, Iftner T. Current methods of testing for human papillomavirus. Best Pract Res Clin Obstet Gynaeco 2001;15:677-700.

11. Gravitt PE, Peyton CL, Apple RJ, Wheeler CM. Genotyping of 27 human papillomavi- rus types by using L1 consensus PCR products by a single-hybridization, reverse line blot detection method. JClin Microbiol 1998 36:3020-7.

12. Van Ranst M, Kaplan JB, Burk RD. Phylogenetic classification of human papillomaviruses: correlation with clinical manifestations. J Gen Virol 1992;73:2653-60.

13. IARC monographs on the evaluation of carcinogenic risks to humans. Vol. 64. Human papillomaviruses. Lyons, France: International Agency for Research on Cancer, 1995.

14. Chaouki N, Bosch FX, Muñoz N, et al. The viral origin of cervical cancer in Rabat Morocco. Int J Cancer 1998;75:546-54.

15. Bayo S, Bosch FX, de Sanjose S, et al. Risk factors of invasive cervical cancer in Mali. Int J Epidemiol 2002;31:202-9.

16. Bosch FX, Muñoz N, de Sanjosé S, et al. Human papillomavirus and cervical intraepithelial neoplasia grade III/carcinoma in situ: a case-control study in Spain and Colombia. Cancer Epidemiol Biomarkers Prev 1993;2: 415-22.

17. Eluf-Neto J, Booth M, Muñoz N, Bosch FX, Meijer CJLM, Walboomers JMM. Human papillomavirus and invasive cervical cance in Brazil. Br J Cancer 1994;69:114-9.

18. Rolón PA, Smith JS, Muñoz N, et al. Human papillomavirus infection and invasive cervical cancer in Paraguay. Int J Cancer 2000;85:486-91

19. Santos C, Muñoz N, Klug S, et al. HPV types and cofactors causing cervical cance in Peru. Br J Cancer 2001;85:966-71.

20. Chichareon S, Herrero R, Muñoz N, et al. Risk factors for cervical cancer in Thailand: a case-control study. J Natl Cancer Inst 1998 90:50-7.

21. Ngelangel C, Muñoz N, Bosch FX, et al. Causes of cervical cancer in the Philippines: a case-control study. J Natl Cancer Inst 1998 90:43-9.

22. Manos MM, Ting $Y$, Wright DK, Lewis AJ, Broker TR, Wolinsky SM. Use of polymerase chain reaction amplification for the detection of genital human papillomaviruses. In: Furth M, Greaves M, eds. Cancer cells. Vol. 7. Molecular diagnostics of human cancer. Cold Spring Harbor, N.Y.: Cold Spring Harbor Laboratory Press, 1989:209-14.
23. de Roda Husman AM, Walboomers JMM van den Brule AJC, Meijer CJLM, Snijders PJF. The use of general primers GP5 and GP6 elongated at their 3' ends with adjacent highly conserved sequences improves human papillomavirus detection by PCR. J Gen Virol 1995;76:1057-62.

24. Myers G, Sverdrup F, Baker C, et al., eds. Human papillomaviruses 1997: a compilation and analysis of nucleic acid and amino acid sequences. Los Alamos, N.M.: Theoretical Biology and Biophysics, Los Alamos National Laboratory, 1997.

25. Breslow NE, Day NE. Statistical methods in cancer research. Vol. 1. The analysis of case-control studies. Lyons, France: International Agency for Research on Cancer 1980. (IARC scientific publications no. 32.) 26. de Sanjosé S, Bosch XF, Muñoz N, et al. Screening for genital human papillomavirus: results from an international validation study on human papillomavirus sampling techniques. Diagn Mol Pathol 1999;8:26-31. 27. Herrero R, Hildesheim A, Bratti C, et al. Population-based study of human papillomavirus infection and cervical neoplasia in rural Costa Rica. J Natl Cancer Inst 2000;92: 464-74.

28. Durst M, Dzarlieva-Petrusevska RT, Boukamp P, Fusenig NE, Gissmann L. Molecular and cytogenetic analysis of immortalized human primary keratinocytes obtained after transfection with human papillomavirus type 16 DNA. Oncogene 1987;1:251-6. 29. Storey A, Pim D, Murray A, Osborn K, Banks L, Crawford L. Comparison of the in vitro transforming activities of human papillomavirus types. EMBO J 1988;7:1815-20.

30. McDougall JK. Immortalization and transformation of human cells by human papillomavirus. Curr Top Microbiol Immunol 1994;186:101-19.

31. Kleter B, van Doorn LJ, Schrauwen L, et al. Development and clinical evaluation of a highly sensitive PCR-reverse hybridization line probe assay for detection and identification of anogenital human papillomavirus. J Clin Microbiol 1999;37:2508-17.

Copyright (c) 2003 Massachusetts Medical Society. 